\title{
A durable pollination raincoat for hybridization during monsoon in coconut
}

\author{
K. Devakumar*, Regi Jacob Thomas ${ }^{1}$ and Anitha Karun \\ ICAR-Central Plantation Crops Research Institute, Kudlu P.O., Kasaragod-671 124, Kerala, India \\ ICAR-CPCRI, Regional Station, Kayamkulam, Alappuzha-690 533, Kerala, India
}

(Manuscript Received: 22-02-2020, Revised: 07-09-2020, Accepted: 09-10-2020)

Keywords: Coconut, ground pollination, hybridisation, rainy season hybridisation

There is a huge demand for coconut hybrid seedlings as it has proven advantages over the local ecotypes in terms of higher yield and resistance/ tolerance to biotic and abiotic stresses. In high rainfall zones, particularly in the western coast of India, coconut hybridization work is carried out only for six months from November to May and pollination work is suspended during rains from June to October. In Southern Kerala,where there is intermittent rainfall even during the dry months (November and May), the fruit set was only 18-19 per cent (Thomas et al., 2012) compared to an average fruit setting of 25 per cent obtained upon artificial pollination in other areas (Nair et al., 2003). The use of polythene covers to prevent wetting of pollination bag has met with little success due to lifting and tossing of the polythene covers during heavy winds and high humidity which accumulates thereupon, that prevents efficient fruit setting. To narrow down the coconut hybrid seedlings demandsupply gap, it was a long-felt desire by researchers and private nursery growers to carry out hybridization even during the rainy season. Besides, in recent years, due to climate change, rainfall is experienced even during non-rainy seasons, affecting coconut hybridization work. The major impediments to carrying out the hybridization during monsoon are the slippery trunks that make repeated tree climbing a risky option, less availability of pollen and the wetting of pollination bag. The recent improvements in the manual climbing device that can aid climbing through the slippery trunk, the ground pollination technique (Devakumar et al., 2018) and coconut pollen cryopreservation techniques (Karun et al., 2014) offers scope to do pollination during monsoon also. We report the development of a reusable raincoat to cover the pollination bag with provisions for attaching the ground pollination system.

This raincoat is designed to withstand heavy winds with provisions for air circulations to prevent humidity build-up. The pollination raincoat is fabricated in two sizes to suit the tall and dwarf inflorescences. The raincoat is open stem-loop structured and fabricated using transparent PVC sheet of $0.30 \mathrm{~mm}$ thickness. It has three sides, and the two lateral sides are made with two separate transparent PVC sheets while the bridging side is made with a single piece of rexin cloth. The seamed region of the isolation bag is stitched with a $5 \mathrm{~mm}$ plastic tube to provide stiffness to the bag. At the bottom of the bridging rexin cloth $(15 \mathrm{~cm}$ above the edge), a window of $10 \times 10 \mathrm{~cm}$ is provided on both sides to facilitate air circulation. A waterproof inserting tube ( $20 \mathrm{~cm}$ length and $2.0 \mathrm{~cm}$ diameter) is provided at the top of the isolation bag for the pollen delivery tube of coconut ground pollination system. The raincoat weighs $500 \mathrm{~g}$, and the narrow base provides air inflow/circulation while preventing humidity build-up and protects the raincoat from being air drifted. A long zipper of 45 $\mathrm{cm}$ in length is provided on one side to fit the

*Corresponding Author: k_devakumar@yahoo.com 


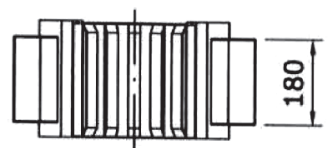

Front view
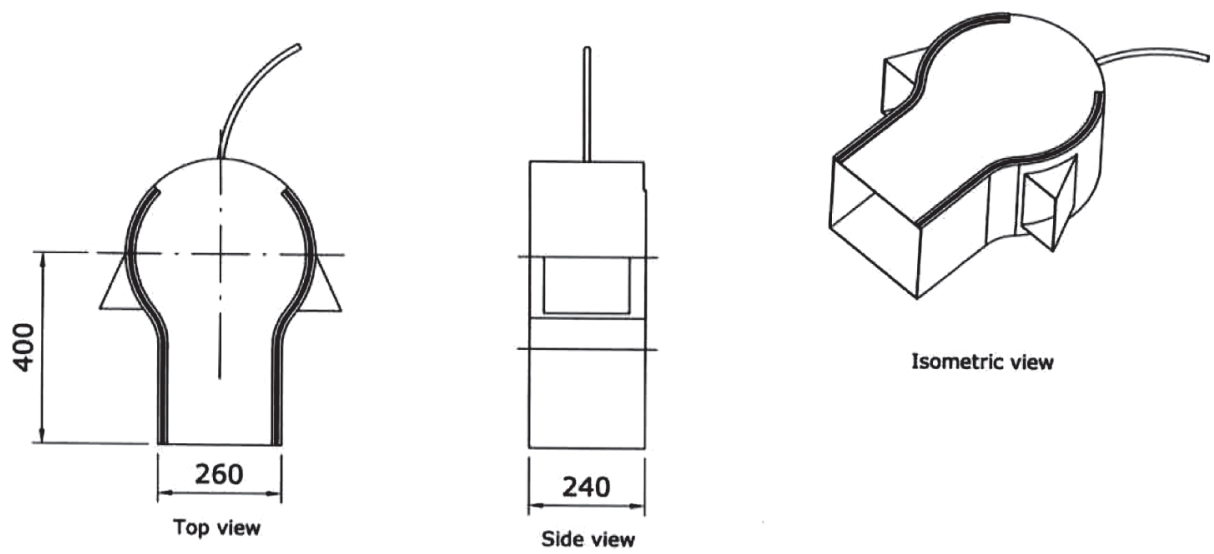

\section{Details of rain bag}

Fig. 1. Monsoon pollination raincoat with side openings to facilitate air circulation

raincoat on the emasculated coconut inflorescence easily. A carry bag is also provided so that the raincoat can be folded, stuffed inside and carried on the shoulder while climbing the coconut palm by the climber.

The climber needs to climb the palm only once to install the ground pollination system, and the rest of the operations can be done from the ground. At first, the climber fits the pollen delivery tube to the waterproof tube of the raincoat, and inside the raincoat, the tube end is tied to the isolation bag. The climber then climbs the coconut palm with the raincoat, pollination bag and the pollen delivery tube. After reaching the crown, he emasculates the male flowers and covers the inflorescence first with isolation bag and then on top of it covers with the raincoat and zips it. The pollen delivery tube remains suspended from the tree, and the pollen is pumped from the ground for four to five days during the receptive female phase. The final bag removal is done similarly as the ground pollination system and the whole unit falls to the ground without any damage to the inflorescence. The raincoat protects the isolation bag against the heavy monsoon rains and keeps it dry, facilitating the fruit setting (Fig. 1). Two sizes of raincoats were designed for Tall and Dwarf coconut palms, respectively. The size of the raincoat for the tall palms was 75X55 $\mathrm{cms}$ and that for dwarfs was $60 \mathrm{X} 40 \mathrm{cms}$.

The monsoon pollination raincoat was tested for its usefulness during monsoon season. The bagging of inflorescence and covering the pollination bag with raincoat was carried out in an emerging inflorescence. The development and maturity of the female flowers were observed daily. Normal development of the female flower was observed during the one week observation period. The pollination was carried out for successive four

Table 1. Details of nut setting with the pollination raincoat

\begin{tabular}{lllcccc}
\hline $\begin{array}{l}\text { Sl. } \\
\text { No. }\end{array}$ & Location & Variety & $\begin{array}{c}\text { No. of } \\
\text { palms }\end{array}$ & $\begin{array}{c}\text { No. of } \\
\text { female flowers }\end{array}$ & $\begin{array}{c}\text { No. of } \\
\text { nuts set }\end{array}$ & $\begin{array}{c}\text { Nut setting } \\
(\%)\end{array}$ \\
\hline 1. & ICAR-CPCRI, Kayamkulam & West Coast Tall & 1 & 80 & 18 & 22.5 \\
2. & ICAR-CPCRI, Kayamkulam & West Coast Tall & 1 & 88 & 20 & 22.7 \\
3. & ICAR-CPCRI, Kasaragod & West Coast Tall & 1 & 29 & 12 & 41.3 \\
\hline
\end{tabular}




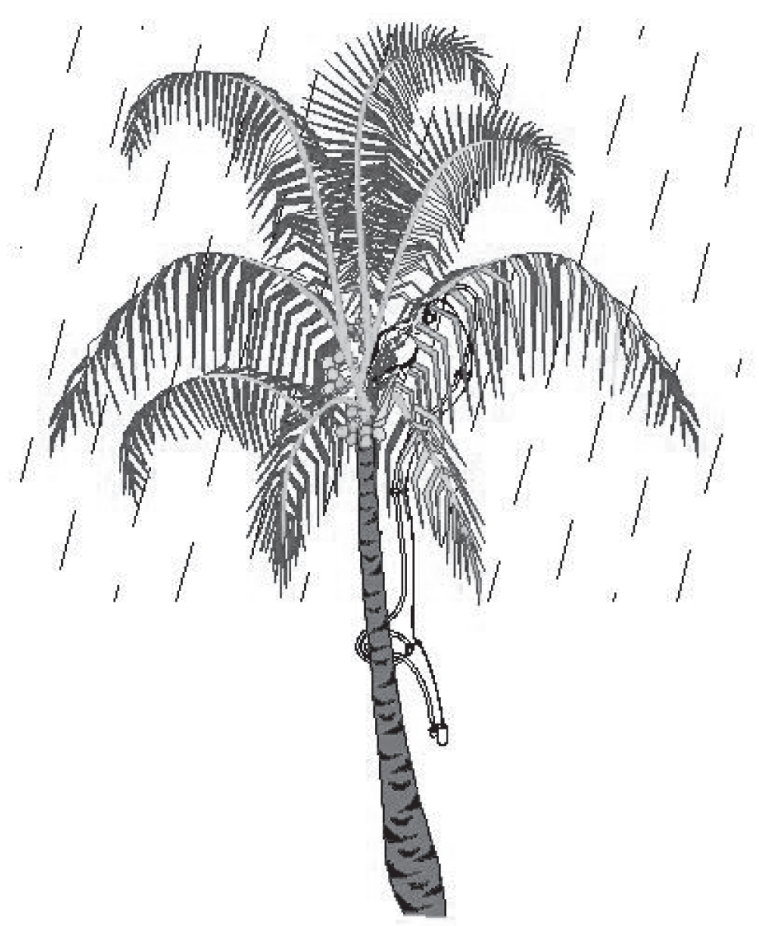

Monsoon Pollination system

Fig. 2. Representative image of raincoat protecting the isolation bag from heavy monsoon rains

days by pumping pollen through a pollen delivery tube and the pollination bag was removed after a week. In case of a tall palm tested at ICAR-CPCRI, Kasaragod, out of the 29 female flowers, 12 female flowers developed into normal nuts. In comparison, the other 17 female flowers were either aborted/ dried. The experiment was also carried out at the ICAR-CPCRI Regional Station, Kayamkulam on two tall palms. In these two palms, the percentage of fruit set was 22.5 and 22.7, respectively (Table 1).

This pollination raincoat prevents rainwater entry and moisture accumulation inside the pollination bag. The presence of a good ventilation system prevents humidity and ensures dryness of the pollination bag even during heavy rainfall. The transparent and waterproof material ensures enough light inside the bag. The provision of zippers on the sides of the raincoat makes it easy to fit it over the pollination bag. The use of this raincoat can ensure pollination work carried out throughout the year and has the potential to double the coconut hybrid seed nut production in the monsoon high rainfall areas (Figs. 2 and 3).
Production of hybrid seed nut is beset with seasonal problems like monsoon rain which restricts the hybridisation programmes. Usually, a mother palm on which pollination (hybridization) is carried out for six months yields 36-42 nuts on an average. If the raincoat covered pollination bag technique is adopted, it could result in double the production of hybrid seed nuts (72-84 nuts per year). If 100 mother palms are available for hybridization, the recovery of hybrids seedlings is usually $1500-1600$. By adopting the raincoat attached pollination bags, the recovery of hybrid seedlings from 100 mother palms can also be doubled to 3000-3200. This simple technique can ensure enhancement in coconut hybrid nuts production throughout the year in areas with heavy rains, and it could also save labour and ensures safety.

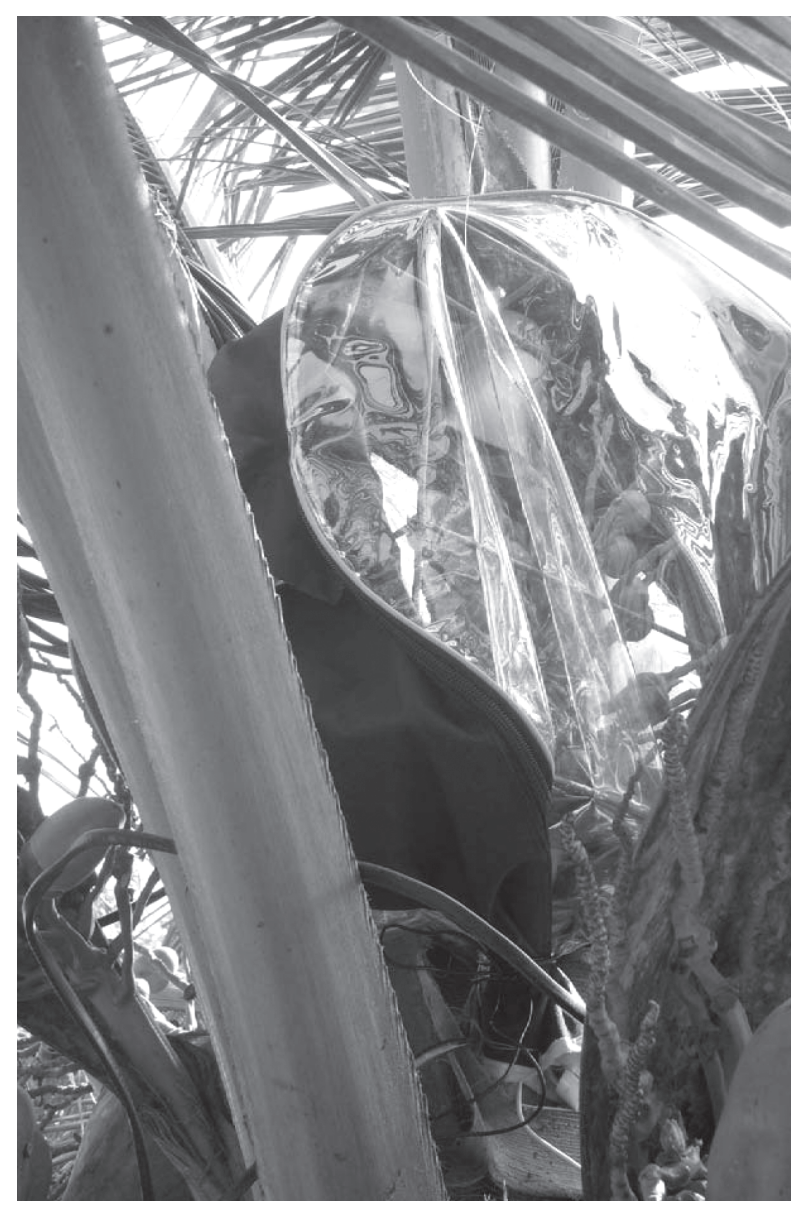

Fig. 3. Image of raincoat fitted coconut tree in the field 


\section{Acknowledgement}

We greatly acknowledge the facilities provided by Director, ICAR-CPCRI and Head, ICARCPCRI, Regional Station, Kayamkulam for carrying out this work.

\section{References}

Devakumar, K., Arumuganathan, T., Thomas, R. J., Niral, V., Karun, A. and Chowdappa, P. 2018. A cost-effective ground pollination system for hybridization in tall coconut palms. Current Science 114(5): 964-970.
Karun, A., Sajjini, K.K., Niral, V., Amarnath, C.H., Remya, P., Rajesh, M.K., Samsudeen, K., Jerard, B.A., Engelmann, F. 2014. Coconut (Cocos nucifera L.) pollen cryopreservation. Cryo Letters 35(5): 407-417.

Nair, R.V., Jacob, P.M., Sasikala, M., Thomas, R. J. and Mathews, C. 2003. Studies on nut setting in artificial pollination of coconut (Cocos nucifera L.). Journal of Plantation Crops 31(3): 53-54.

Thomas, R. J., Nair, R.V., Mathews, C., Ajithkumar, R. and Nampoothiri, C. K. 2012. Studies on fruit set in coconut upon artificial pollination in various cross combinations. Indian Journal of Horticulture 69(1): 7-12. 